\title{
O que Fanon disse, afinal? \\ Lewis Gordon e a defesa de uma abordagem fanoniana*
}

\author{
Deivison Mendes Faustino ${ }^{a}$
}

GORDON, Lewis R. What Fanon Said: A Philosophical Introduction to His Life and Thought. New York: Fordham University Press, 2015.

\begin{abstract}
O que eu queria dizer a você [...] é que a morte está sempre conosco e que o importante não é saber como evitá-la, mas ter certeza de que fazemos o nosso melhor pelas ideias que acreditamos. A única coisa que me choca, desenganado nesta cama e perdendo as forças do meu corpo, não é que eu estou morrendo, mas que eu estou morrendo de leucemia aguda em Washington, DC, quando eu poderia ter morrido há três meses, de frente para o inimigo no campo de batalha, quando eu já sabia que tinha esta doença. Nós não somos nada nesta terra, se não servirmos antes de tudo uma causa, a causa do povo, a causa da liberdade e da justiça. Eu quero que você saiba que, mesmo quando os médicos tinham perdido toda a esperança, eu ainda estava pensando, em uma névoa concedida, mas pensando, no entanto, no povo argelino, nos povos do Terceiro Mundo [...]. Se eu consegui segurar, foi por causa deles ("Carta de despedida ao seu amigo Roger”, Fanon apud Gordon, 2015, p.141-2).
\end{abstract}

A obra What Fanon Said: a philosophical introduction to his life and thought, do filósofo jamaicano Lewis R. Gordon, oferece grandes contribuições aos estudos sobre a vida e obra de Frantz Fanon. O autor, que também é conhecido pelas publicações Bad Faith and Anti-black Racism (1995), Fanon and the Crisis of European Man: An Essay on Philosophy and the Human Sciences (1995) e por divulgar a obra fanoniana ao redor do mundo, dessa vez, vem a público no ano que se celebra os 90 anos de Frantz Fanon para apresentar sua reflexão, adquirida ao longo de mais de 20 anos de pesquisa.

A partir de uma filosofia radical, que critica as raízes e os efeitos do racismo global, Lewis Gordon problematiza, de maneira singular, as categorias sujeito, razão, racialização, subalternização, colonialismo, violência, desejo, práxis, etc.,

\footnotetext{
Este trabalho contou com apoio do Programa CAPES 194 - Programa de Doutorado Sanduíche no Exterior, processo: 99999.003766/2014-04.

a Doutor em Sociologia pelo Programa de Pós-Graduação em Sociologia da Universidade Federal de São Carlos - PPGS-UFSCar.
} 
abrindo, portanto, um diálogo crítico com as principais vertentes teóricas das ciências sociais contemporâneas e apontando para a possibilidade de um novo humanismo pós-colonial (Nissim-SABAT, 2011).

Ao utilizar um método de análise e de escrita que relaciona a vida, a obra e o contexto social da produção de Fanon, o autor se opõe às tendências de reduzir o intelectual martinicano à sua biografia, argumentando que "não é a biografia de Fanon que nos traz a seus escritos e realizações políticas, mas seus escritos e realizações políticas que nos trazem a sua biografia” (GoRdON, 2015, p.10). O posicionamento expressa sua preocupação com aquilo que nomeia como identidade teórica subordinada, ou seja, a inclinação a subestimar a capacidade intelectual de teóricos negros. Dentro dessa abordagem reducionista, ou Fanon é apresentado enquanto edipiano ansioso, perturbado, atormentado pelo ódio e, ainda, preso à própria experiência, ou então é reduzido a uma das matrizes teóricas com que dialogou.

Com isso, Gordon nos provoca ao lembrar que Jean Paul Sartre se inspirou em Aimé Césaire, Léopold Sédar Senghor e no próprio Frantz Fanon; Simone de Beauvoir fez o mesmo com Richard Wright; e Max Weber com W.E.B. Du Bois. Ainda assim, não se vê classificações de Sartre como césairiano, senghoriano ou fanoniano, tampouco de Beauvoir como wrightiana ou Weber como duboisiano; pois, mesmo nas raras vezes em que se identificam algumas dessas influências nos autores do chamado mainstream, reconhece-se sempre que eles foram além de suas "fontes".

No entanto, o mesmo não ocorre quando o autor é negro. Talvez por isso que muitos estudos se limitam a discutir, sem consenso, se Fanon é marxista, pós-estruturalista ou até mesmo sartreano - sem, com isso, se debruçarem sobre suas contribuições. É a partir dessa constatação, e em contraposição a ela, que What Fanon Said se propõe a entender como o autor martinicano logrou desenvolver as ideias de seu tempo em outro nível, sobretudo quando comparado às suas fontes, e, principalmente, de que maneira essas ideias oferecem um conjunto original de críticas e soluções para os problemas teóricos e práticos que persistem até os dias de hoje.

Como psiquiatra humanista, filósofo e revolucionário, Frantz Fanon deixou uma marca indelével no pensamento e na política do século XX, e sua influência continua a crescer em nosso século. Todavia, em referência à sua localização social e histórica, diversos autores defendem a necessidade de "trabalhar com" algumas de suas ideais, utilizando filtros que nos evitem empolgar com suas afirmações humanistas ou revolucionárias (AlESANDRINI, 1999; 2014; BHABHA, 1996; HALL, 1996; Sсотт, 1999). Em um caminho distinto, Gordon se aproxima das preocupações 
de Cedric Robinson (1993), Benita Parry (1994) e Jane Gordon (2011) para apontar o que identifica como arbitrariedade seletiva desse argumento: não apenas Fanon deve ser entendido em seu contexto, mas, também, as leituras contemporâneas que se propõem a retomar partes de seu pensamento, sem, contudo, assumirem o compromisso com o conjunto de sua reflexão. Fruto de um momento em que as alternativas radicais ao sistema deixaram de estar na ordem do dia, a crítica se restringiu a constatar a dinâmica racista da situação colonial (GoRdon, 2015, p.18).

Gordon reconhece a existência e a pertinência das "leituras" foucaultianas, marxistas, derridarianas, deleuzianas, sartreanas, entre outras, para a consolidação do que nomeia Fanon Studies. Em adição ao debate, lança as seguintes provocações: o que Fanon disse, afinal? O que nos impediria de assumir uma leitura fanoniana dos problemas levantados pela sociedade contemporânea? Quais seriam os elementos úteis nas obras de Fanon para a compreensão da realidade em suas mais atualizadas, e ainda complexas, dimensões coloniais?

Essas e outras questões são problematizadas pelo autor ao longo de cinco capítulos que apresentam os textos fanonianos em ordem cronológica, observando-os, quando possível, a partir de seu contexto individual e/ou sócio-político de produção. O diálogo estabelecido revela a posição de Fanon sobre grandes temas das ciências humanas contemporâneas, de modo a oferecer uma abordagem bastante sofisticada e, ao mesmo tempo, acessível a respeito de suas contribuições.

O primeiro capítulo, intitulado "I Am from Martinique", parte das reflexões sobre o corpo para, assim, introduzir a trajetória de vida e pensamento de Fanon: "O corpo é o homem, e o homem, seu corpo"; o problema é que esse corpo - quando negado pelas agressividades coloniais - é uma presença negada. Segundo Gordon, a escrita de Fanon reflete essa "urgência nascida da intimidade" de quem vivenciou a negação, mas, sobretudo, optou por confrontá-la (GoRdon, 2015, p. 8).

Esse corpo “negado por ser muito corpo" (GoRDON, 2015, p.9), continua Gordon, nasceu em 25 de julho de 1925, dois meses depois de Malcolm Xe algumas semanas depois de Patrice Lumumba, em uma colônia francesa no Caribe chamada Martinica. Para o filósofo jamaicano, essa localização é importante para se entender as batalhas políticas, psíquicas e teóricas que Fanon travou. Seu alistamento às forças militares francesas contra as ocupações fascistas, bem como seu posterior engajamento na campanha de Aimé Césaire para presidente pelo Partido Comunista, nos oferece certa intimidade com o autor martinicano e suas ideias.

Depois de participar da campanha política de Césaire, Fanon aproveitou seu status de veterano de guerra para se candidatar a uma bolsa de estudos para odontologia em Paris. Nesse momento, Gordon brinca com a ideia equivocada de 
um "revolucionário premeditado": "Um dentista revolucionário? Pode-se imaginar os muitos trocadilhos terríveis que surgiram" caso este caminho se concretizasse. Fanon “agarraria as garras da história para chegar à raiz da opressão” (GoRDON, 2015, p.13). Todavia, Fanon decide mudar de curso e se direciona à cidade de Lyon para estudar psiquiatria forense, profissão que combinaria seus interesses nas investigações das ciências naturais e humanas. Em Lyon, local onde estudavam os prestigiados filósofos Jean Lacroix e Maurice Merleau-Ponty, Fanon logra enriquecer seu repertório teórico e se arrisca a escrever pequenos ensaios.

O primeiro deles, La plainte de Noir: L'expérience vécu du Noir (1951), compôs a sua primeira tese de doutorado, intitulada "Essai sur la désalienation du Noir" - a qual fora rejeitada por seu orientador por questionar o mainstream positivista da época. Em resposta, Fanon escreve outra tese em apenas duas semanas, chamada "Troubles mentaux et syndromes psychiatriques dans l'Hérédo-Dégénération-Spino-Cérébelleuse: Un cas de maladie de Friedreich avec délire de possession", defendendo-a, com sucesso, em 1951. No ano seguinte, publica o texto rejeitado na primeira tese, sob o título Peau noire, masques blancs (1952). É a partir das problematizações contidas nesse texto seminal e, sobretudo, tomando-o como guia filosófico privilegiado que Gordon elabora sua reflexão filosófica para propor a descida ao que Fanon chamou de verdadeiros infernos da existência. Para Gordon, a escrita de Fanon apresenta-se ora como um Dante, que, movido pelo amor incondicional ao humano, dispõe-se a enfrentar o incerto, ora como um Virgílio, que nos orienta ao longo do difícil declive.

O Segundo e o terceiro capítulos, "Writing through the Zone of Nonbeing Living Experience" e "Embodying Possibility", respectivamente, vão retomar a noção de paradoxo existencial, de Kierkegaard, para discutir dois grandes temas que ele destaca em Peau noire, masques blancs, quais sejam: a zona do não-ser (zone of nonbeing) e a experiência vivida do negro. Para ele, ao se perguntar "o que o negro quer?”, Fanon estaria, na verdade, explicitando a traumática relação entre corpo, desejo, razão e racialização: a experiência europeia, o branco e o ocidente são discursivamente deificados (teodicy) ao serem elevados, discursivamente, ao patamar de universalidade. Tal deificação faz com que suas próprias falhas sejam transferidas para aquilo que se acredita estar fora dela ou no "lado negro" do próprio sistema; nessa medida, o negro é reduzido à esfera do não humano para, então, amargar a invisibilidade do limbo ou o inferno de uma aparição indesejada - a tal zone of nonbeing (GoRdon, 2005; 2015).

O filósofo jamaicano chama a atenção para o fato de que não é só o Negro que é racializado, mas também as noções de ser, humanidade, universalidade, razão, 
filosofia, etc., ao serem apresentadas como atributos essencialmente brancos. O que o Negro quer é ser um homem entre outros homens (FANON, 1952); mas a experiência vivida do negro ${ }^{1}$ revelaria o paradoxo de se deparar com o Branco, posto sempre como teodicy, e a si próprio como polo oposto dela. O paradoxo existencial que está posto é aceitar o sistema, sem nem ao menos ser considerado parte dele, ou denunciar essa razão racializada, sem, no entanto, incorrer no irracionalismo (GoRDON, 2015).

A ideia de sociogenia, oferecida por Fanon, é retomada ao longo de What Fanon Said como pressuposto que articula, dialeticamente, as dimensões subjetivas e objetivas da existência humana para identificar, na exploração capitalista e, sobretudo, nas racializações que a sustenta, os elementos que alienam (subjetiva e objetivamente) a humanidade, de maneira a restringir sua liberdade. $\mathrm{O}$ colonialismo, em seus múltiplos tentáculos, representa a interdição do reconhecimento hegeliano e a impossibilidade dos negros - poderíamos pensar, em acréscimo, dos palestinos, da comunidade LGBTT, dos Sem-Terra, dos povos originários do Continente Americano, das mulheres e outros, a depender do tempo e do espaço - de serem vistos e, principalmente, de se verem como humanos em meio a outros humanos.

É nesse sentido que o quarto e o quinto capítulos, "Revolutionary Therapy" e "Counseling the Damned", respectivamente, relacionam dois aspectos pouco problematizados na literatura brasileira sobre Fanon: as reflexões e práticas clínicas e a luta política enquanto alternativa para superar a alienação colonial. Em 1951, Fanon se dirige ao Hospital de Saint Alban para realizar seus estudos de residência médica, sob a supervisão de François Tosquelles, um dos principais formuladores da reforma psiquiátrica e manicomial, defensor de uma prática médica que pensa a relação entre social e político. Gordon destaca que os estudos de Tosquelles apontavam possibilidades concretas de superação de alguns problemas identificados em Peau noire, masques blancs: se as alienações psíquicas têm origem em uma sociedade que milita contra a humanidade das pessoas, logo, sua superação passaria,

1 É importante dizer que o termo "experiência vivida do Negro" (The Lived Experience of the Black) é a tradução inglesa que Gordon propõe para "L'expérience vécue du Noir", título do quinto capítulo de Pele negra, máscaras brancas. Segundo o autor jamaicano, a tradução utilizada no mundo anglófono, "The fact of blackness" ("o fato da negrura"), de C. Lam Markmann (1967), oculta a dimensão fenomenológica do capítulo, que é, segundo ele, o ponto alto do livro. Para o autor, as discussões oferecidas nesse capítulo são visivelmente inspiradas no subtítulo de $O$ segundo sexo: experiência vivida (Le Deuxième sexe. Tome 2: L'expérience vécue, 1949), de Simone de Beauvoir, livro onde, não por acaso, a filósofa francesa reconhece ter recebido influências diretas de Richard Wright para a formulação de sua reflexão sobre "tornar-se mulher". Gordon lembra, ainda, que o termo "L'expérience vécue", sempre muito caro ao existencialismo, fora introduzido pelo francês Maurice Merleau-Ponty, inspirado no conceito alemão de Erlebnis, amplamente utilizado por Fanon (GoRdon, 2015). 
necessariamente, pela transformação da sociedade. Essa posição, argumenta ele, fica nítida nos experimentos clínicos de Fanon em Blida, em seu engajamento na Frente de Libertação Nacional da Argélia e, sobretudo, nas reflexões teóricas e políticas que ofereceu a partir desse período.

Para Gordon, os escritos produzidos no período revelam a coerência de Fanon e não a ruptura - com preocupações apontadas em seu primeiro livro; porém, aqui, a luta política em curso oferecia a possibilidade de dar fim à interdição colonial. Os escritos de Sociologie d'une révolution ([1959] 1968), Lés damnés de la terre (1961) e Pour la révolution africaine ([1964] 1969) sugerem que é a luta de libertação que gera liberdade, afirmando, com efeito, a emergência do sujeito. Essa luta, entretanto, se quiser evitar armadilhas que estão postas, deve rejeitar tanto o universalismo abstrato da teodiceia europeia, como os particularismos reificados que se alimentam do ódio. A descolonização, como terapia revolucionária, teria a função catártica de possibilitar que o sujeito assuma consciência de si, mesmo que para tanto seja preciso colocar valores ocidentais contra si próprios, em vez de simplesmente rejeitá-los.

What Fanon Said oferece uma contribuição capital para as ciências humanas contemporâneas, mormente em uma época tão plena de contradições. Diante do contínuo e sistemático genocídio do povo palestino; das possíveis influências dos grandes centros de poder no surgimento do ISIS, Taleban e Boko Haran; dos sistemáticos assassinatos cometidos por policiais nas periferias brasileiras; da manutenção de uma imagem estereotipada a respeito de mulheres e negros; do crescimento do fundamentalismo cristão e do conservadorismo em geral; da inabilidade da "esquerda" para reconhecer e enfrentar o racismo - ou da hegemonia política, teórica e ideológica das teorias fomentadoras da fragmentação -, entre outros elementos postos pela realidade social contemporânea, a obra What Fanon Said nos provoca a encarar esses problemas não para simplesmente descrevê-los ou apresentar uma nova visão, tampouco para “tremer de indignação” (FANON, 2008) diante deles, mas, sobretudo, para assumir nossas tarefas históricas (FANON, 2010).

\section{REFERÊNCIAS BIBLIOGRÁFICAS}

ALESSANDRINI. A. C. Introduction: Fanon studies, cultural studies, cultural politics. In: ALESSANDRINI. A. C. (Ed.) Frantz Fanon: Critical perspectives. London/New York: Ed. Rutledge, 1999.

Frantz Fanon and the Future of Cultural Politics: Finding Something Different. Lanham: Lexington Books, 2014. 
BHABHA, H. Day by Day... with Frantz Fanon. In: READ, A. (Ed.) The fact of blackness: Frantz Fanon and visual representation. Seattle: Bay Press, 1996.

FANON, F. Peau Noire, Masques blancs. Paris: Editions Du Seuil, 1952. Pour la révolution africaine (écrits politiques). Cahiers Libres. $\mathrm{n}^{\mathrm{os}} \cdot$ 53-54. François Maspero, 1964.

. Les damnés de la terre. Paris: Librairie François Maspero Éditeuir, 1961. Sociologia d'une révolution. «L'an V de la Revólution algerienne ». Paris: François Maspero, 1968.

. Pele negra, máscaras brancas. Salvador: EDUFBA, 2008.

. Os condenados da terra. Juiz de fora: Ed. UFJF, 2010. . Pour la révolution africaine. Paris: Maspéro, 1969.

GORDON, J. A. Revolutionary in Counter-Revolutionary Times: Elaborating Fanonian National Consciousness into the Twenty-First Century. Journal of French and Francophone Philosophy. Revue de la philosophie française et de langue française. Vol. XIX, n. 1, p.37-47, 2011.

GORDON, L. R. Bad Faith and Anti-black Racism, Atlantic Highlands. New York. Humanities Press, 1995a.

. Fanon and the Crisis of European Man. New York: Routledge, 1995b. . Through the Zone of Nonbeing: A Reading of Black Skin, White Masks in Celebration of Fanon's Eightieth Birthday: The C.L.R. James Journal 11, n .1, p.1-43, Summer 2005.

What Fanon Said: A Philosophical Introduction to His Life and Thought. New York: A Fordham University Press Publication, 2015.

HALL, S. The After-life of Frantz Fanon: Why Fanon? Why Now? Why Black Skin, White Masks? In: READ, A. (Ed.) The Fact of Blackness: Frantz Fanon and Visual Representation. London: Institute of Contemporary Arts and International Visual Arts, 1996.

NISSIM-SABAT, M. "Lewis Gordon's Phenomenological Critique of the New World

Consciousness". Radical Theory and Theory of Communication. Atlantic Journal of Communication, n. 19. p. 28-42, 2011.

PARRY, B. Postcolonial studies: a materialist critique. London: Routledge, 1994.

ROBINSON, C. The Appropriatton of Frantz Fanon. Race and Class, vol. 35, n. 1, July/ September 1993.

SCOTT, D. Refashioning Futures: Criticism After Postcoloniality. Princeton: Princeton University Press, 1999.

Recebido para publicação em: 03/05/15. Aceito para publicação em: 26/06/15. 